\title{
Autoconstrução - reflexões sobre a demanda de assistência técnica a partir de estudo de caso em Uberlândia - MG
}

\section{Vera Lúcia Serralha Mendes*}

Ricardo Moretti**

\section{Resumo}

O artigo apresenta uma reflexão sobre a demanda de assistência técnica para a construção gerida pelo próprio morador, a partir de estudo realizado no município de Uberlândia-MG. No estudo são entrevistados moradores de 25 residências que foram auto construídas no âmbito de uma iniciativa da prefeitura municipal de distribuição de "plantas populares pré-aprovadas". São casas isoladas com área predominantemente superior a $50 \mathrm{~m}^{2}$, edificadas em terrenos praticamente planos, com área superior a $240 \mathrm{~m}^{2}$. Situam-se em um bairro afastado da área central que conta, todavia, com infra-estrutura completa. Na maior parte dos casos a construção contou com apoio de mão de obra com experiência na construção civil, pelo menos em parte da obra. Foram encontrados resultados bastante positivos, em termos de qualidade da edificação e satisfação dos moradores, o que enseja a reflexão sobre as características da assistência técnica a ser fornecida para os diferentes tipos de iniciativas de autogestão da construção habitacional.

\section{Palabras clave}

Habitação Popular; Autoconstrução; Autogestão da Construção; Assistência Técnica para Habitação.

\section{Resumen: Autoconstrucción - reflexiones sobre la demanda de asistencia técnica a partir de un estudio de caso en Uberlandia-MG}

El artículo analiza la demanda de asistencia técnica para la construcción gestionada por el propio usuario, a partir de un estudio realizado en Uberlândia-MG. En dicho estudio se entrevistó a los residentes de 25 viviendas que habían sido autoconstruidas por estos usuarios. Las viviendas se realizaron en el marco de una iniciativa del gobierno municipal, que incluía la distribución de los "proyectos populares pre-aprobados". Se trata en la mayoría de los casos de viviendas aisladas, con una superficie superior a $50 \mathrm{~m}^{2}$, construidas en terrenos casi planos de superficie superior a $240 \mathrm{~m} 2 . \mathrm{Se}$ encuentran en un barrio fuera de la zona central que tiene, sin embargo, infraestructura completa. En la mayoría de los casos, la construcción pudo contar con trabajo de apoyo de personas con experiencia en construcción civil, al menos en parte de la obra. Los resultados fueron muy positivos en términos de calidad y satisfacción de los residentes, llevando a reflexionar sobre las características de la asistencia técnica más adecuada a los diferentes tipos de iniciativas de autogestión en la construcción de viviendas.

\section{Palabras clave}

Vivienda Social; Autoconstrucción, Autogestión de la Construcción; Asistencia Técnica para la Construcción de Vivienda. 


\section{Abstract: Demand of technical assistance in self built social housing - Uberlândia case study}

In this paper it is discussed the demand of technical assistance for civil construction in cases where the building process is conducted and managed by the owner, based upon a case study in Uberlandia- MG. The residents of 25 self constructed- houses were interviewed. These houses were produced as part of a local government program, which delivers "pre-approved projects for building social housing". Most of the house have more than $50 \mathrm{~m}^{2}$ and built in plots bigger than $240 \mathrm{~m}^{2}$. They are located in a low-income neighborhood, with complete infra-structure. In most of the houses, there can be noticed the presence of contracted workers with some kind of civil construction skills. A very positive result was found regarding quality of the construction and residents satisfaction, which leads to a discussion of the characteristics and frequency of technical assistance required for different kinds of self-managed social housing.

\section{Key words}

Social Housing; Self-Construction, Self-Managed Civil Construction, Technical Assistance for Social Housing Projects.

\section{Introdução}

Em que pese o grande esforço para ampliação do mercado formal de produção e comercialização da habitação de interesse social no Brasil, verificado nos últimos anos, é bastante provável que, em um futuro próximo, a maior parte das habitações destinadas à população de baixa renda ainda seja resultante de processos de produção que envolvem a autogestão da construção. Essa perspectiva não difere daquela encontrada em outros países da América Latina. No Brasil, de acordo com os dados dos censos realizados pelo Instituto Brasileiro de Geografia e Estatística (IBGE) entre 2000 e 2010 foram construídos em média 1,25 milhões de novos domicílios particulares a cada ano. Tem-se um contingente ainda maior de domicílios que são reformados anualmente. Estudo realizado pela Booz, Allen \& Hamilton, em 2003, mostra que a construção autogerida representava $67 \%$ do valor investido e $77 \%$ do total de unidades habitacionais produzidas (Associação Brasileira de Desenvolvimento Industrial, 2009, p.138)

São ainda pequenos os resultados alcançados em termos de fornecimento de assistência técnica para essa enorme demanda, que está fora do mercado formal da construção habitacional. Os órgãos governamentais, as empresas e os profissionais de construção civil manifestam sua preocupação com o Quadro, mas ainda são tímidos os resultados da aproximação com aquele que gerencia sua própria construção. Na América Latina existem algumas iniciativas que merecem destaque, entre elas a da Sociedade de Arquitetos do Uruguai, que em 1998 criou o programa "Arquitectos de la Comunidad" com o objetivo de aproximar as pessoas dos serviços de arquitetura. Foram implantadas unidades de atendimento pelo país e criadas planilhas que contemplavam os custos dos serviços dos profissionais (Sociedad de Arquitectos del Uruguay, 2011). Em Cuba e no Equador, propostas de assessoria individualizadas para reforma e construções são oferecidas em iniciativa semelhante à uruguaia. A cimenteira mexicana Cemex por meio do programa "Patrimonio Hoy" concede financiamento para a compra de material de construção juntamente com assessoria técnica ao autoconstrutor, desde a execução do projeto até a conclusão da obra, oferecendo também capacitação de mão-de-obra (Pralahad, 2005).

No Brasil, algumas iniciativas recentes merecem destaque, como a aprovação da Lei 11.888/2008, 
que assegura às famílias de baixa renda assistência técnica pública e gratuita para o projeto e a construção de habitação de interesse social. Ou ainda a criação, em junho de 2010, do Clube da Reforma. Trata-se de um movimento que une empresas privadas e organizações sociais para gerar soluções estratégicas para transformar 0 setor de reformas de moradias e tem como meta facilitar o acesso e melhorar a qualidade da habitação para um milhão de famílias de baixa renda até 2014 (Clube da Reforma, 2011).

O apoio à autoconstrução, na forma de uma política pública institucionalizada, é criticada por Francisco de Oliveira, que aponta a autoconstrução como um modo de rebaixar o custo de reprodução da força de trabalho:

"Eu diria que a industrialização brasileira foi sustentada por duas fortes vertentes. A primeira foi a vertente estatal, pela qual o Estado transferia renda de certos setores e subsidiava a implantação industrial. $E$ a segunda eram os recursos da própria classe trabalhadora, que autoconstruía sua habitação e com isso rebaixava o custo de reprodução" (Oliveira, 2006, p. 2).

No mesmo artigo, Francisco de Oliveira critica a precariedade das casas autoconstruídas, apontando-as como "aglomerações infernais, onde a promiscuidade e a vida privada não têm fronteiras" (ob. cit, p.1). Por um lado, não há como negar a importância do questionamento da exclusão dos custos habitacionais do salário do trabalhador. Nesse sentido segue também a argumentação de Raquel Rolnik, professora da Faculdade de Arquitetura e Urbanismo da Universidade de São Paulo e relatora da ONU para o direito a moradia que, em palestra proferida na 3a Jornada da Moradia Digna realizada em São Paulo em fevereiro de 2011, destacou que nunca entrou na composição do valor do salário mínimo no Brasil a previsão de gastos relativos à moradia, em que pese a habitação ser um direito constitucional no país. Por outro lado não se pode aceitar a si- tuação atual em que, não somente o trabalhador é levado a produzir sua própria moradia, mas é também levado a produzi-la sem assistência técnica e muitas vezes em terrenos sem condições adequadas de urbanização. Ou seja, ainda mais injusto que a autoconstrução é mantê-la na sua forma atual.

Também é necessário questionar as afirmações sobre a precariedade de edificação produzida por autogestão. É grande e diferenciado o Quadro encontrado nas obras realizadas pelos próprios interessados. É comum a contratação de algum tipo de mão de obra especializada em alguma fase da obra. Varia muito o tipo e a qualidade da assistência técnica que o responsável pela construção consegue acessar. Varia muito a qualidade do produto final.

Sobre a estética da habitação social, Victor Pelli (2004) destaca que é indispensável afirmar o direito do habitante a ser partícipe, com ampla quota de decisão, na definição geral de sua habitação, inclusive na sua definição estética. Já em 1994, o mesmo autor apontava a necessidade de considerar o conceito de "necessidades habitacionais básicas", contemplando o que os habitantes consideram imprescindíveis para gerar, como mínimo, situações estáveis e bases sólidas para uma evolução física e social das condições de moradia (Pelli, 1994). No livro "Habitar, Participar e Pertenecer", publicado pela primeira vez em 2007, o autor condensa as reflexões sobre as diversas formas de produção da habitação social e questiona o paradigma de entrega da habitação pronta, como eixo único ou central de uma política de habitação social (Pelli, 2010). No mesmo sentido estão as preocupações de Rubén Sepúlveda, quando analisa as políticas urbanohabitacionais no Chile (Ocampo et al, 2009).

Como contribuição para o entendimento desse Quadro, resgata-se nesse artigo a pesquisa realizada em Uberlândia, em 2002, que se dá em um 
caso específico e favorável à produção autogerida. Nesse Quadro favorável chega-se a resultados muito positivos em termos de qualidade da habitação e satisfação dos moradores, o que enseja a reflexão sobre as características, o tipo e a freqüência de assistência técnica em situações semelhantes. $\mathrm{Na}$ ocasião foram entrevistadas famílias cuja renda mensal se enquadrava na faixa de até 5 salários mínimos, que na época correspondia a $R \$ 1000,00$ ou US $\$ 430,00$, ou seja, em um momento em que o salário mínimo correspondia a US\$86,00. Esse dado traz à tona a rápida mudança do salário mínimo do trabalhador brasileiro, que é de $R \$ 622,00$, o que corresponde a cerca de US \$310,00 em junho de 2012.

\section{Pesquisa realizada}

Para avaliar a política de apoio à autoconstrução em Uberlândia- MG, realizou-se uma pesquisa com famílias que viabilizaram a compra de um terreno e a obtenção dos materiais, agenciaram a

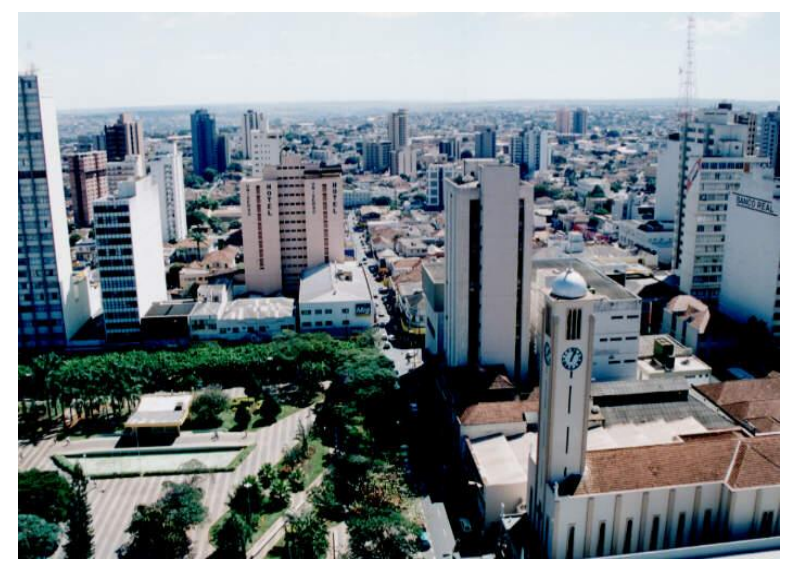

mão-de-obra gratuita ou remunerada informalmente e, em seguida, ergueram suas moradias (Mendes, 2002).

Uberlândia é uma cidade localizada no Triângulo Mineiro, em um pólo de interligação das regiões Sul, Oeste, Norte e Nordeste do Brasil. O tronco rodo-ferroviário e Porto Seco do Cerrado são fatores preponderantes para seu desenvolvimento e acelerado crescimento populacional, a ritmos mais elevados que aqueles observados no Estado. Com uma população em 2010 de 600.285 habitantes é o terceiro município de Minas Gerais. Apesar do crescimento acelerado, Uberlândia apresenta uma infra-estrutura básica (água encanada, energia elétrica e coleta de esgoto) que atende a quase totalidade dos domicílios, colocando-a acima da média brasileira. Em contrapartida, é uma cidade de fortes contrastes e desigualdades, entre as áreas bem estruturadas $\mathrm{e}$ os bairros onde se concentram os extratos de mais baixa renda.

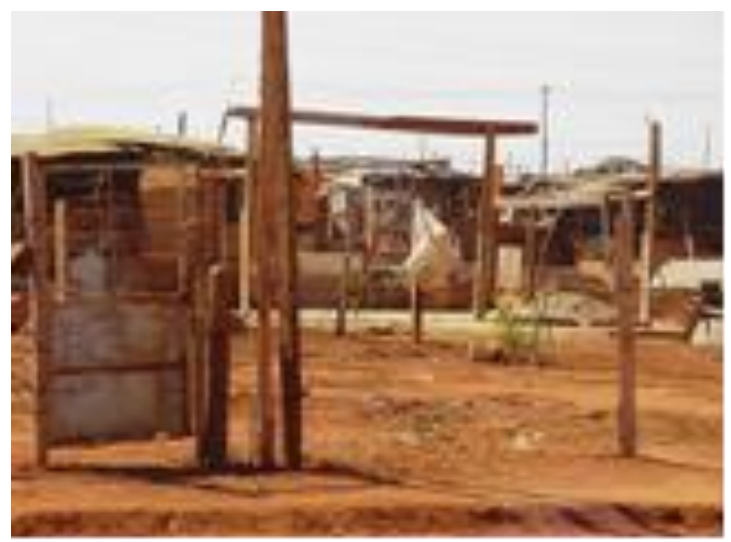

Figura 1. Vista da cidade. Fonte: <www.uberlandia.mg.gov.br.> Figura 2. Favela. Fonte: Vera Mendes.

Uberlândia pôde contar com uma quantidade razoável de unidades habitacionais produzidas por meio de diversos programas governamentais. Isto não impediu a permanência de um déficit habitacional, representado, em uma parte, pelos que não estavam inseridos no mercado de trabalho formal e, noutra, pelos que não suportavam os valores cobrados pelos aluguéis e financiamentos. Nestas condições, intensifica-se o número de construções irregulares e clandestinas como também o aparecimento de áreas ocupadas e a formação de favelas. A autoconstrução mostra-se então, como a forma mais usual de provisão habitacional da população de baixa renda.

Ao reconhecer a importância desta produção, a Prefeitura Municipal passa a oferecer um serviço de fornecimento de Plantas Populares às famílias com renda de até 5 salários mínimos, que pos- 
suam o terreno para construção (não é necessário que o mesmo esteja quitado; a Prefeitura aceita o contrato de compra e venda no lugar da escritura).

As possibilidades de implantação e regularização deste serviço perante o CREA-MG, Conselho Regional de Engenharia, Arquitetura e Agronomia de Minas Gerais, são garantidas pelo Art. $2^{\circ}$ do Ato $n$ ㅇ. 03/84, que dispensa o Responsável Técnico, a pedido do proprietário, nas obras residenciais unifamiliares, destinadas a uso próprio, com área inferior a $60 \mathrm{~m}^{2}$, sem concreto armado ou laje pré-moldada. Para se obter a planta popular junto à Prefeitura, além dos documentos pessoais, é necessária a comprovação de renda dentro da faixa mencionada, a escritura ou contrato de compra e venda e o pagamento de uma taxa para expedição do alvará de licença para construção. A Prefeitura oferece 16 tipos de plantas, com dimensões e características arquitetônicas variadas.

Informações sobre modificações do projeto escolhido são repassadas no ato da entrega da planta, cuja orientação se faz no sentido da permissão de alterações desde que não ultrapassem o limite máximo de área. Além destas, outras informações são fornecidas por meio de um formulário entregue intitulado "Regulamentações Fundamentais de Projeto para Planta Popular". Orientações sobre procedimentos ao término da obra dizem respeito à solicitação do habite-se e averbação em cartório. Quando se consegue concluir todo o processo, após a emissão do habite-se, a Secretaria de Obras envia ao Cadastro cópia do projeto executado para emissão da Certidão de Averbação, que posteriormente será registrada no Cartório de Registro de Imóveis.

Visando analisar esta política de apoio à autoconstrução foram aplicados questionários a 25 famílias de acordo com a seguinte metodologia. A amostra foi selecionada dentro dos setores Sul e Oeste da cidade de Uberlândia por classificaremse em $1^{\circ}$ e $2^{\circ}$ lugares, respectivamente, na incidência deste tipo de construção. A seleção das famílias entrevistadas se deu aleatoriamente, a partir do fornecimento, pela Prefeitura, de 90 fichas cadastrais sendo, 45 datadas de 2001 e 45 de anos anteriores. A mescla de datas foi feita para que fosse possível identificar problemas que incidem de forma diversa nos diversos estágios da construção e pós-construção. Tomou-se o cuidado de incluir visitas durante a semana como também nos sábados e domingos, dias em que se intensificam os trabalhos da autoconstrução. Dados sobre as famílias entrevistadas revelam que $72 \%$ não são naturais de Uberlândia e que $64 \%$ são sustentadas por uma só pessoa do grupo familiar. Quando se considera a renda familiar (Quadro 1) tem-se 50\% das famílias com renda entre 1 e 2 salários mínimos da época, que era de US 86,00 .

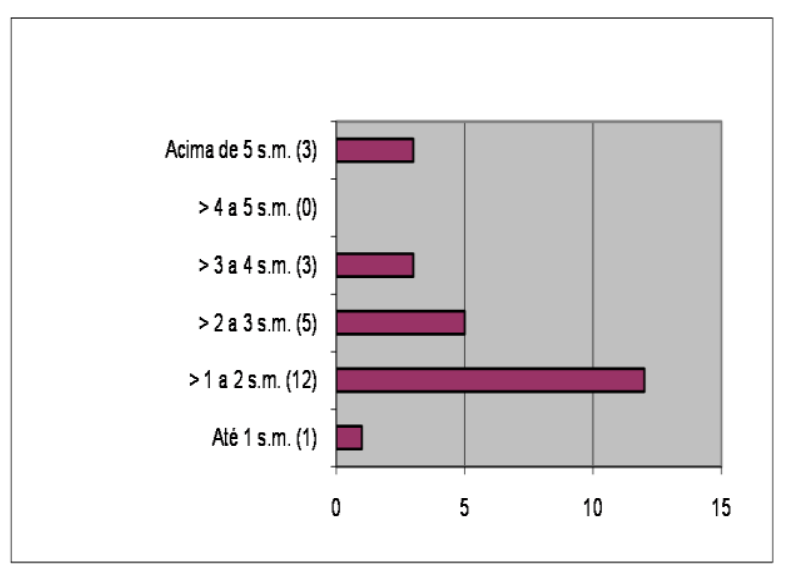

Quadro 1. Faixa salarial familiar da população pesquisada, em salários mínimos (s.m).

O número de moradores por domicílio varia significativamente, conforme pode ser verificado no Quadro 2. A densidade habitacional média da moradia apresentou-se um pouco superior àquela apontada pelo Censo do IBGE em 2000 (Quadro 3). Das 25 propriedades, apenas 4 possuíam mais de 1 domicílio por lote (casa de fundos). 


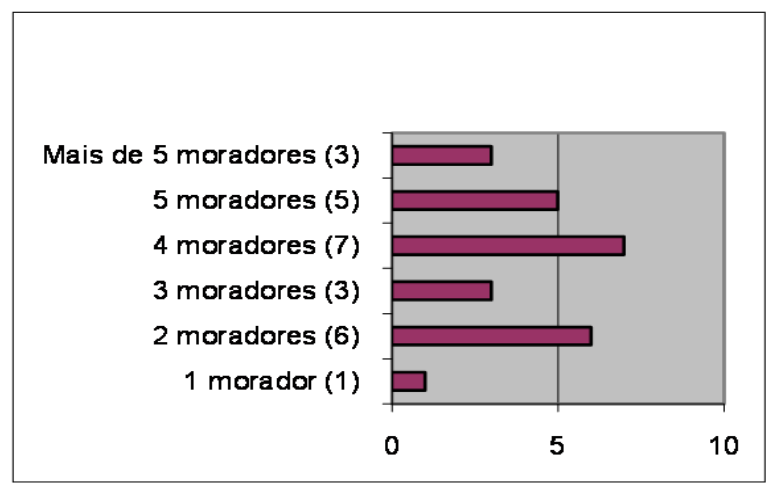

Quadro 2. Número de moradores na casa principal do lote.

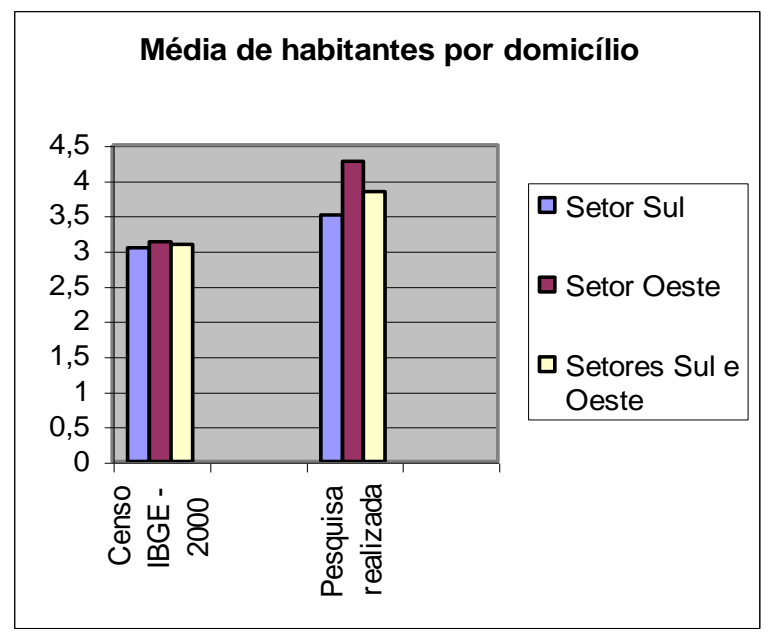

Quadro 3. Número médio de habitantes por domicílio.

Em relação aos recursos utilizados para obtenção do terreno, verificou-se que em $36 \%$ dos casos foram utilizados recursos próprios (Quadro 4). Já na compra do material de construção predominam os recursos próprios, que foram utilizados em $76 \%$ dos casos.

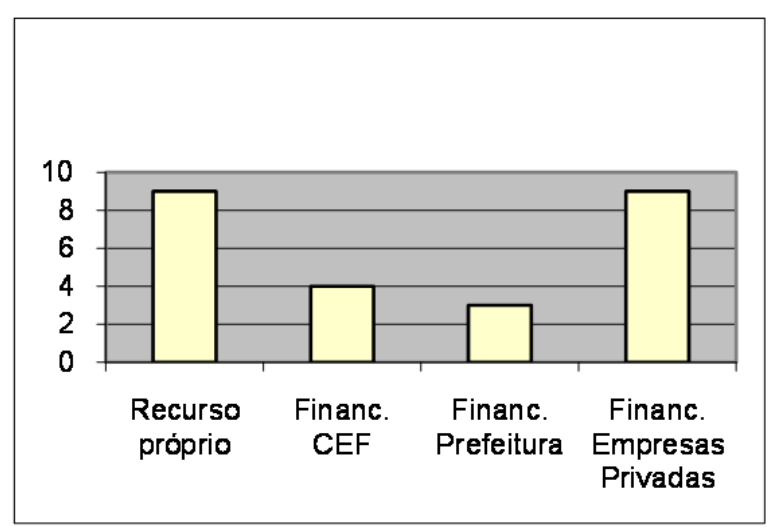

Quadro 4. Recursos utilizados para compra do lote.
Questionados sobre os motivos que levaram à procura do serviço de fornecimento de plantas populares pela Prefeitura, a maioria manifesta a expectativa de estar em situação regular e legalizada (Quadro 5). É elevada a satisfação com o serviço oferecido pela Prefeitura, que é aprovado por $68 \%$ dos entrevistados, sendo que $92 \%$ dos beneficiários responderam que, se necessário, retornariam à Prefeitura para nova obtenção de planta para construção.

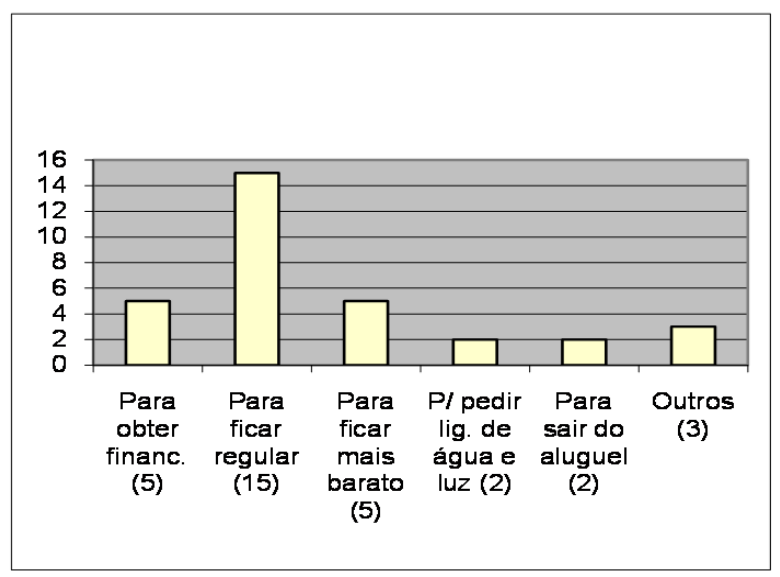

Quadro 5. Motivo da procura pelo fornecimento de planta na Prefeitura.

Dentre os 16 tipos de projetos oferecidos, a escolha maior recaiu sobre os projetos com área superior a $50 \mathrm{~m}^{2}$ (Quadro 6). Vale destacar que a pretensão não é a de construir em sua totalidade e sim, contar com uma ampliação planejada (72\% pretendem aumentar a edificação ou construir varanda) e a Prefeitura tem uma postura coerente nesse sentido, pois orienta sobre possíveis acréscimos ou modificações.

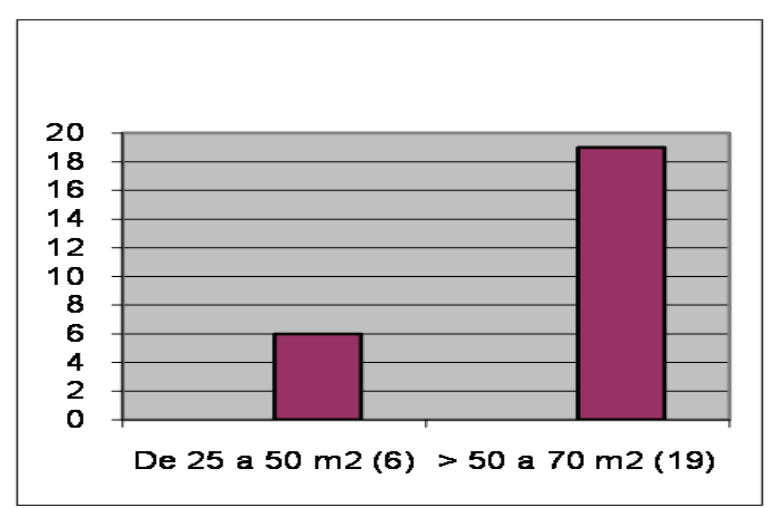

Quadro 6. Área de construção dos projetos selecionados pelos moradores. 
O número de proprietários que tinham experiência em construção civil corresponde a 52\% do total, pouco superior, portanto, ao percentual de $48 \%$ dos proprietários que não tinham experiência prévia. No Quadro 7 apresenta-se o arranjo montado para obtenção da mão-de-obra e, no Quadro 8, são mostradas as preferências pela qualificação profissional, caso pudessem pagar pelos serviços, verifica-se que a escolha concentra-se nos pedreiros e serventes, seguida dos mestres de obras. Os entrevistados julgam não ser necessária a presença de engenheiros e/ou arquitetos em obras simples como as que são empreendidas. Vale destacar que as edificações foram produzidas rapidamente: $56 \%$ das edificações foram produzidas em até 4 meses, $24 \%$ demoraram de 4 meses a um ano, e apenas $20 \%$ das edificações foram produzidas em um prazo superior a um ano.

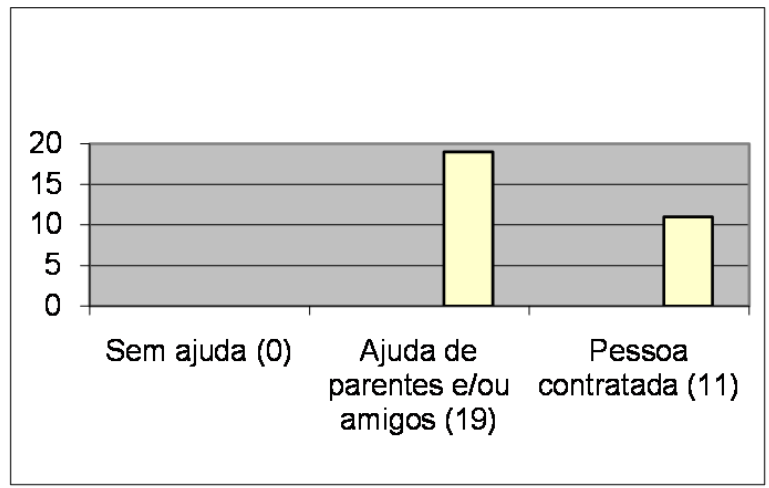

Quadro 7. Solução adotada para a mão de obra.

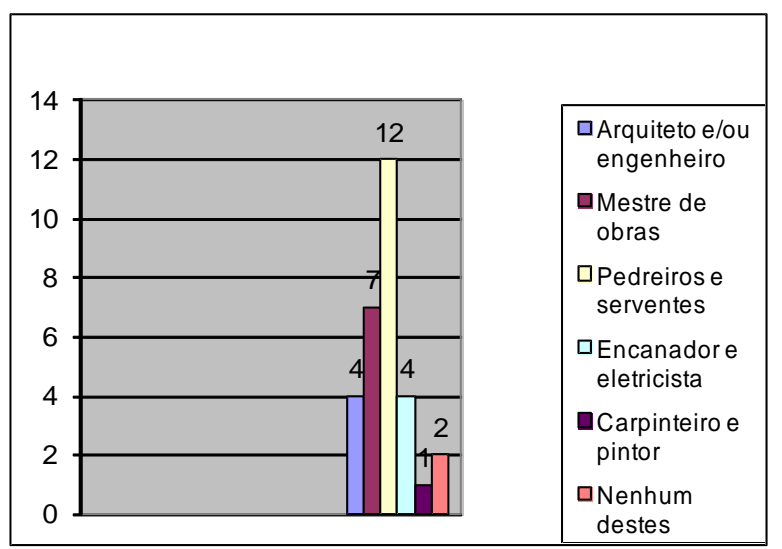

Quadro 8. Preferência por profissional caso pudessem pagar.

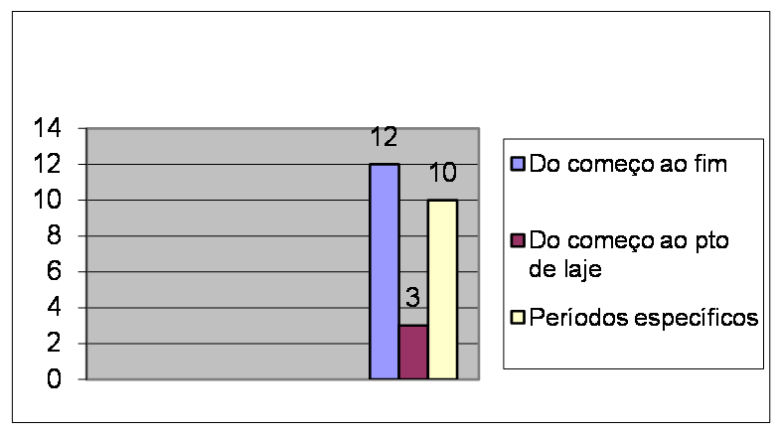

Quadro 9. Etapas da obra em que foi recebida ajuda.

No Quadro 9 são indicadas as etapas da obra em que houve ajuda para a edificação. Verifica-se uma predominância da ajuda do "começo ao fim" da obra. Embora essa alternativa pressuponha a "conclusão da obra", esta é uma condição rara, dificilmente encontrada no âmbito da autoconstrução da classe de menor renda. Esta situação indica a presença contínua da ajuda no decorrer de sua produção. É importante acrescentar que a mão-de-obra recebida como ajuda, de parentes e/ou amigos, por 19 famílias, era de pessoas com experiência na construção civil. Verifica-se assim uma população onde é grande a concentração de trabalhadores da construção civil.

Um grande desafio, durante a pesquisa de campo, foi o de identificar os problemas e dificuldades enfrentadas pelos autoconstrutores. Quando questionados, a maioria respondia não ter nenhum tipo de problema ou dificuldade, razão esta da apresentação de dois gráficos. O primeiro gráfico, de respostas não induzidas (Quadro 10), e o segundo, sintetizado a partir de colocações sobre dificuldades nos serviços de instalações elétricas ou hidráulicas, serviços de carpintaria, falta de ferramental adequado, dentre outras (Quadro 11). A dificuldade técnica, nos poucos casos em que foi apontada, refere-se a uma série de fatores que vão desde a escolha, compra e preparo dos materiais; marcação e nivelamento da obra; execução e/ou fiscalização dos serviços; reconhecimento e identificação de problemas estruturais ou daqueles que podem ser prejudi- 
ciais à construção como o caso de infiltrações, dentre outros. A dificuldade com a disponibilidade de mão de obra diz respeito à diferença de horários disponíveis entre as pessoas que se dispuseram a ajudar e também com relação aos serviços que, para serem executados, dependem de que outro esteja concluído, tornando-se necessário aguardar a disponibilidade da pessoa que irá executá-lo.

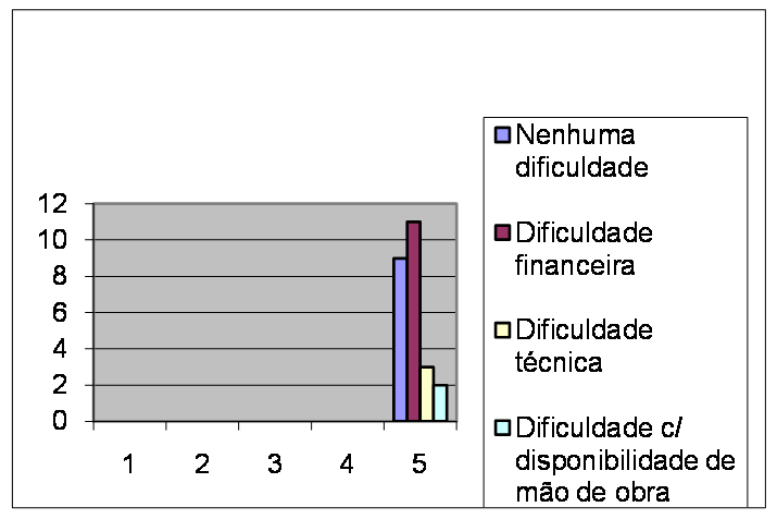

Quadro 10. Problemas e dificuldades na autoconstrução - respostas não induzidas.

Por último, verificamos que existe uma grande satisfação das famílias em relação ao resultado final da construção, considerado bom ou muito bom por $60 \%$ dos entrevistados. Apenas 2 entre os 25 entrevistados consideraram ruim o resultado final obtido. Uma média de $73 \%$ de respostas positivas para as adequações de segurança (estrutural), beleza das construções e de conforto térmico, acústico e lumínico confirmam esta con dição. A despeito da possível influência da falta de acabamento em relação ao conforto térmico (laje sem cobertura do telhado), acústico (inexistência de portas internas) e lumínico (falta de revestimento nas paredes e piso). No quesito beleza, destaca-se que a grande maioria dos moradores considera bonita sua residência, apesar de não concluído o acabamento.

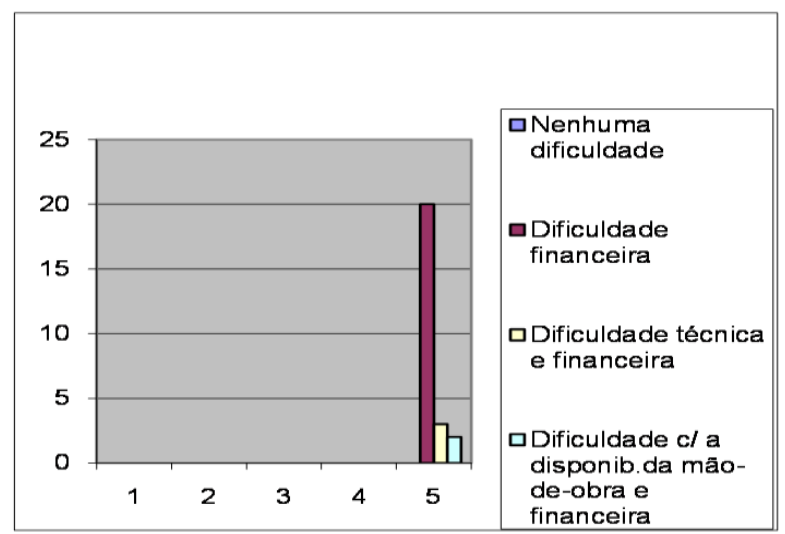

Quadro 11. Problemas e dificuldades na autocontrução - respostas induzidas.

Há também a aprovação do bairro em que moram, considerado bom ou muito bom por $76 \%$ dos entrevistados. Verifica-se a satisfação quanto às condições de infra-estrutura (água encanada, energia elétrica, coleta de esgoto, pavimentação, guias e sarjetas, rede telefônica) e serviços como transporte coletivo e coleta de lixo. Manifestam demanda pela instalação de posto de saúde e posto policial (Quadro 12).

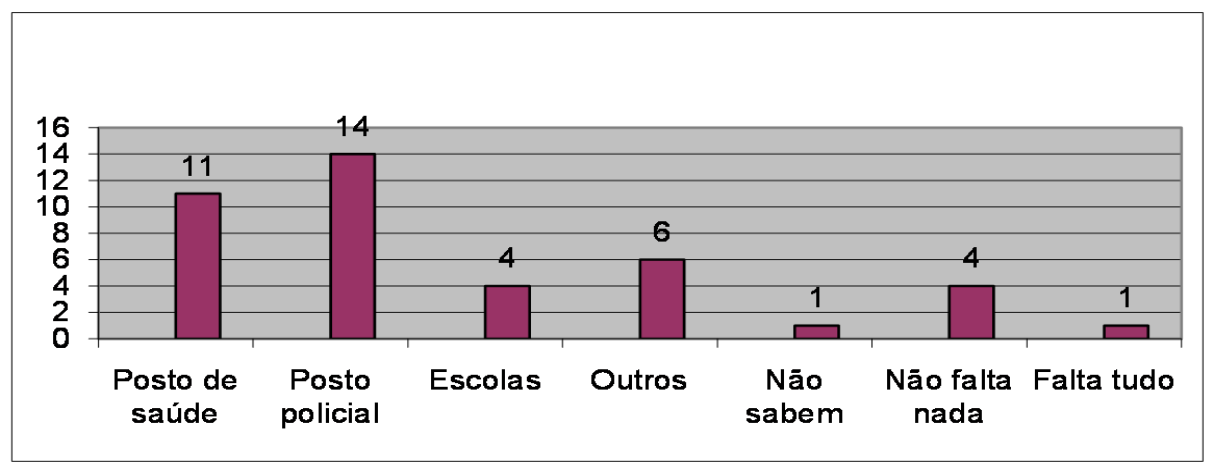

Quadro 12. Itens mais solicitados nos bairros.

Antes das conclusões, é necessário reafirmar que a análise foi realizada em uma situação que envolve: 1) lotes relativamente grandes, a menor área encontrada foi de $240 \mathrm{~m}^{2}$; 2) edificações isoladas no lote, não houve situações de casas geminadas e somente 4 dos 25 lotes possuíam 
mais de uma habitação; 3) terrenos de baixa declividade variando, na maior parte, de $2 \%$ a $5 \%$; 4) boa capacidade de suporte para fundações, não se encontrando solo mole em nenhum dos lotes visitados; 5) presença de infra-estrutura nos bairros.

\section{Discussão dos resultados}

O levantamento realizado não confirmou a hipótese inicial do estudo, de que se encontraria um Quadro precário de qualidade da edificação resultante da autoconstrução. Surpreendeu o fato da maioria não apontar dificuldades técnicas na execução dos serviços nas diversas etapas de produção da moradia. Os resultados foram submetidos ao teste estatístico do "Qui-quadrado", através do qual foi possível constatar que as famílias que não apresentaram dificuldades de qualquer tipo foram aquelas que receberam ajuda em tempo integral. As famílias receberam ajuda em períodos específicos, queixaram-se de dificuldades relacionadas a este tipo de apoio, denominado de "ajuda picada".

Os incentivos e facilidades oferecidos aos autoconstrutores são de grande importância e devem ser assumidos pelos governantes em parceria com outras instituições e com a sociedade civil organizada. $\mathrm{O}$ alto nível de satisfação encontrado entre a população assistida pelos serviços de fornecimento de plantas populares pela Prefeitura Municipal demonstra que pequenas ações podem dar certo, bastando que se verifiquem quais são as necessidades e prioridades apontadas. Podese considerar que o passo dado ocorre na direção do "direito à legalidade" que, na prática, é negado a uma parte considerável da população de baixa renda, por não conseguir fazer frente aos gastos e às dificuldades administrativas envolvidas na regularização da documentação de sua construção.

Identifica-se na permanência desta política públi- ca uma condição básica: a manutenção de rumos e diretrizes administrativas, de assistência e apoio, de estudos e pesquisas, como também a manutenção do volume de recursos para a aplicação no setor habitacional. Decorridos 10 anos da pesquisa realizada em Uberlândia- MG buscou-se uma atualização de dados junto à Prefeitura Municipal, bem como junto às pessoas que autoconstroem suas casas, de forma a resgatar o cenário descrito na pesquisa, sua alteração ou ainda a manutenção do modelo descrito nesse sistema de construção. Foi possível constatar que a Prefeitura Municipal, de uma forma geral, mantém o programa, embora o nome da iniciativa se altere a cada nova administração. Os serviços de fornecimento de plantas populares se mantêm com as mesmas características e requisitos mostrados na pesquisa realizada. São 16 tipos de plantas que variam de 25 a 70 metros quadrados. Atendem famílias de até 5 salários mínimos, é cobrada uma taxa de $\mathrm{R} \$ 30,00$ (trinta reais) e está em estudo a implantação de serviços de assistência técnica durante a obra, aos autoconstrutores. A iniciativa se insere também no âmbito do programa de regularização de bairros, notadamente nos que se formam através do processo de ocupação de áreas. Esta iniciativa envolve o cadastramento das famílias em situação de vulnerabilidade social, fornecimento de plantas populares, parcerias em projetos de Habitação de Interesse Social (HIS) firmados com o Estado, cooperativas, ONGs, movimentos sociais e iniciativa privada, com financiamentos de lotes e kit's de materiais para a construção.

\section{Entrevistas com autoconstrutores-2011}

Ainda na perspectiva de atualizar o cenário da pesquisa realizada em 2002, a ONG Ação Moradia foi contatada, que viabilizou a reunião com representantes de outras 30 famílias para entrevistas a respeito do processo de autoconstrução que vem sendo executado ao longo desses anos. 
Ressalta-se que desse grupo mais de $60 \%$ contou com a participação ativa de mulheres na autoconstrução, quando não, executada somente por estas. Primeiramente, levantou-se o processo de aquisição dos lotes para a construção. Os lotes foram comprados à vista ou financiados. $\mathrm{A}$ maioria comprou os lotes com pagamento à vista, em dinheiro, de particulares, cujo preço variava de $R \$ 300,00$ (trezentos reais) a $R \$ 5.000,00$ (cinco mil reais) conforme estivessem vazios ou já com início de construção. As compras e vendas se dão extra contratualmente; vale apenas 0 combinado. A origem dos lotes vem de processos de ocupação de terras, ou seja, a base do negócio é a confiança no vendedor e a esperança em ser beneficiado no processo de regularização e assentamento de famílias desenvolvido pela Prefeitura Municipal. Já os lotes financiados, geralmente são originados de doações feitas pela Prefeitura a ONGs ou associações dedicadas ao atendimento de famílias carentes.

Quanto aos materiais para a construção, estes são comprados à vista ou financiados a juros elevados pelas lojas de materiais de construção ou, ainda, obtidos em entulhos de demolições espalhados em vários pontos da cidade. A ajuda recebida em todo o processo da autoconstrução continua sendo a denominada "ajuda picada". Não é a ideal, pois nem sempre as famílias podem contar com esta ajuda nos dias estabelecidos ou pactuados, o que resulta em atraso da obra. Geralmente é formada por serventes e pedreiros. A dificuldade maior foi verificada em relação à marcação da obra (esquadrejamento da alvenaria) e, nas instalações hidráulicas e elétricas. Se pudessem escolher a qualificação da ajuda recebida, esta seria voltada aos mestres de obras, por considerarem que estes reúnem todo o conhecimento necessário nas diversas etapas da construção.

A maioria manifesta grande satisfação com o resultado obtido, embora relatem problemas como a falta de esquadrejamento das paredes, rachaduras e infiltrações. A falta de acabamento é quase a regra. A pretensão de um dia terminarem a casa é constante e, junto desta, há o desejo de poder contar com uma ajuda qualificada (talvez contratada) para repararem os defeitos e terem a garantia de um bom acabamento.

Ressalta-se que aquelas famílias que participaram de todo o processo ainda mantêm suas casas. Já, as que receberam muito, em termos de doações de materiais e mão de obra, já venderam suas casas. Um grupo destacado que pôde contar com a assistência de um mestre de obras e um pedreiro e, ainda, com o emprego de tijolos ecológicos na construção, relata uma satisfação bem maior em relação ao resultado obtido, já que a casa não apresenta rachaduras ou trincas e não necessita acabamento, eis que os tijolos ficam à vista. A menção a esse tipo de material se faz necessária porque faz parte de um trabalho de grande aceitação que vem sendo realizado junto às famílias carentes pela ONG Ação e Moradia. Fundada em 1993, a Ação Moradia, é uma organização não governamental e filantrópica que vem atuando junto aos bolsões de pobreza de Uberlândia, abrangendo um aglomerado de bairros e assentamentos com mais de 33 mil pessoas. São desenvolvidos programas de capacitação de mão de obra, geração de trabalho e renda.

Dentre os programas desenvolvidos tem-se o chamado "Construção com tijolos ecológicos", secados ao tempo, sem utilização de fornos. É uma estratégia de intervenção social que alia a melhoria da qualidade de vida de famílias em situação de vulnerabilidade social à proteção ambiental. A possibilidade veio com a criação da Fábrica de Tijolos Ecológicos a Aquecedores Solares, fundada em 1993 pela então chamada Pastoral da Família (pastoral da Igreja Católica), 
hoje atual Ação Moradia. As construções com os tijolos ecológicos são modulares e seu manuseio é bastante simples. Não necessita argamassa de assentamento, nem quebra de paredes para embutir encanamento e fiação elétrica, o que contribui também para a redução de entulhos provenientes da construção civil. As casas contam com aquecedores solares fabricados pela própria comunidade e, com isso, a redução no consumo de energia elétrica é de mais de $30 \%$. A partir desse projeto, os aquecedores solares passaram a ser exigência em todos os projetos geridos pela Prefeitura Municipal. As famílias recebem assistência técnica tanto na fabricação dos tijolos, aquecedores solares, como também, na execução da construção.

Conclui-se, portanto, pela importância de se criar um mecanismo de assistência técnica às pessoas que autoconstroem suas moradias, mesmo porque se trata de uma realidade inexorável. A comprovação se dá tanto pela superior qualidade da construção quando essa assistência é emprega$\mathrm{da}$, quanto pelo desenvolvimento de novas alternativas que minimizam os gastos na construção civil, evitando desperdício de material, economizando energia e contribuindo para a melhoria ambiental. Em Uberlândia algumas instituições trabalham no oferecimento de cursos de capacitação de mão de obra, como a FIEMG (Federação das Indústrias do Estado de Minas Gerais). Porém, se faz necessária a criação de um programa que canalize essa melhoria para ajudar aos autoconstrutores, já que estes não podem pagar pela mão de obra qualificada. Assim, a realização do sonho da casa própria continua acontecendo de forma muitas vezes improvisada.

\section{Considerações finais}

O resultado apreendido na pesquisa sobre a autoconstrução mostra a necessidade de ampliarmos os estudos nesta área de modo a minimizar os enormes sacrifícios a que está submetida grande parte da população brasileira. Conforme assinalado anteriormente é grande e diferenciada a realidade encontrada nas obras realizadas pelos próprios interessados. É comum a contratação de algum tipo de mão de obra especializada em alguma fase da obra. Varia muito o tipo e a qualidade da assistência técnica que o responsável pela construção consegue acessar. A assistência prestada pelos profissionais que comercializam materiais de construção é usual e muitas vezes fundamental para assegurar um mínimo de qualidade.

É necessário questionar a afirmação generalizada de que a obra feita por autogestão é de má qualidade. Os órgãos representantes dos engenheiros e arquitetos têm defendido a presença desses profissionais em praticamente todo tipo de construção. É patente a necessidade de ampliar os esforços de fornecimento de assistência técnica àquele que produz sua própria construção, seja de uma nova residência ou de reforma. As recentes tragédias envolvendo os episódios de chuvas intensas no Brasil demonstraram o risco de construções inadequadas em locais inadequados. Patente também a necessidade de ampliar os estudos sobre a patologia das construções e técnicas para seu enfrentamento. Essa assistência inclui um leque de ações e a presença de diversos profissionais, inclusive de engenheiros e arquitetos. Ou seja, não pode se limitar à presença de engenheiros e arquitetos, porque dependendo da freqüência em obra que se estabeleça, deverá haver dificuldades em encontrar profissionais disponíveis para o atendimento de toda a demanda.

Nesse momento, em que se ampliam os esforços para fornecimento de assistência técnica, considera-se importante resgatar os resultados da pesquisa, realizada em 2002 em Uberlândia, em um Quadro bastante específico e favorável à produção auto gerida. Esse não é o único Quadro 
encontrado, mas também não é raro. Seria impróprio compará-lo, por exemplo, com a realidade encontrada na Região Metropolitana de São Paulo, em que, de forma temerária, se constrói praticamente sem assistência técnica em lotes mínimos (da ordem de $40 \mathrm{~m}^{2}$ ) e em terrenos de elevada declividade. Há um trabalho de porte a ser desenvolvido pelos engenheiros e arquitetos, de apoio à população que faz a autogestão da construção. Esse trabalho envolve o acompanhamento das obras realizadas em situações que podem colocar em risco os futuros moradores. Inclui ainda um leque de iniciativas de interação com os profissionais das lojas de material de construção, com pedreiros e demais profissionais da construção civil, no sentido do compartilhamento de saberes e aperfeiçoamento da formação dos Quadros que, na prática, assessoram os que constroem por autogestão. Delimitar com precisão os casos e os momentos em que a presença na obra do profissional de engenharia e arquitetura é imprescindível deve ser uma das iniciativas no sentido de assegurar assistência técnica gratuita e de qualidade, conforme prevê e ampara a legislação recentemente aprovada.

\section{Referencias}

$\begin{array}{lrr}\text { ASSOCIAÇÃO } & \text { BRASILEIRA } & \text { DE } \\ \text { DESENVOLVIMENTO } & \text { INDUSTRIAL- } & \text { ABDI. }\end{array}$

Estudo Panorama Setorial de Construção Civil. Brasília, 2009.

<http://www.abdi.com.br/Estudo/Panorama\%20

Setorial\%20de\%20Constru\%C3\%A7\%C3\%A3o \%20Civil.pdf>. (Consultado em 26 de junho de 2012).

INSTITUTO BRASILEIRO DE GEOGRAFIA E ESTATÍSTICA (IBGE). Censo 2012. Tabela 12. Domicílios particulares permanentes, por condição de ocupação do domicílio, segundo as Grandes Regiões e as Unidades da Federação, 2010. <http://www.censo2010.ibge.gov.br/sinopse/inde x.php?dados $=P 12 \& u f=00>$. (Consultado em 11 de junho de 2012).

INSTITUTO BRASILEIRO DE GEOGRAFIA E ESTATÍsTICA (IBGE). Censo 2000. TabelaDomicílios particulares permanentes e moradores em domicílios particulares permanentes, por situação do domicílio, segundo algumas das principais características do domicílio-Brasil. $<$ <ttp://www.ibge.gov.br/home/estatistica/popula cao/censo2000/tabelabrasil131.shtm>. (Consultado em 11 de junho de 2012).

MENDES, Vera Lúcia Serralha. Habitação de Interesse Social em Uberlândia-MG. Análise de resultados da autoconstrução com o uso de plantas populares. Dissertação (Mestrado em Urbanismo). Pontifícia Universidade Católica de Campinas, 2002.

OLIVEIRA, Francisco de. O vício da virtude: Autoconstrução e acumulação capitalista no Brasil. Novos Estudos Cebrap, 2006, oㅜ 74, p. 1-13.

PELLI, Victor Saúl. Habitar, Participar, Pertenecer: Acceder a la Vivienda: Incluirse en la Sociedad. Buenos Aires: Nobuko, 2010.

PELLI, Víctor Saúl. Autoconstrucción, el camino hacia la gestión participativa y concertada del Habitat. In PELLI, Víctor Saúl et al. Reflexiones sobre la Autoconstrucción del Habitat en America Latina. Cyted, 1994, p. 9-40.

$<$ http://hdrnet.org/71/1/REFLEXIO.pdf>. (Consultado em 26 de junho de 2012).

PELLI, Víctor Saúl. La Casa Bella: Estética, Identidad, Poder y Distorsión de Metas en la Vivienda Social. Cuaderno Urbano, 2004, no 4 , p. 183202.

PRALAHAD, C.K. A riqueza na base da pirâmide. São Paulo: Bookman, 2005. 391 p.

SEPÚLVEDA OCAMPO, Rubén et al. Bicentenario: oportunidad de repensar las políticas urbano-habitacionales en Chile. Revista Invi, 2009, no 67 , p. 21-67. 
SOCIEDAD DE ARQUITECTOS DEL URUGUAY.

$<$ <ttp://www.sau.org.uy/pags/pro_arqCom_IE.ph p>. (Consultado em 04 de março de 2011).

\section{Cita del artículo}

SERRALHA MENDES, V. L. y MORETTI, R. Autoconstrução - reflexões sobre a demanda de assistência técnica a partir de estudo de caso em Uberlândia-MG. Hábitat y Sociedad, 2011, ํo 3, p. 93-105. $<w w w . h a b i t a t y s o c i e d a d . u s . e s>$.

http://dx.doi.org/10.12795/HabitatySociedad.2011.i3.06 